\title{
DESIGN A MOBILE TELEPHONE SYSTEM IN A CERTAIN CITY
}

\author{
Yunus Ucar ${ }^{1,2}$ \\ ${ }^{1}$ Department of Electrical \&Electronics Engineering,Bozok University, Yozgat, Turkey \\ ${ }^{2}$ Department of Information and Communications Engineering, University of Leicester, Leicester, UK
}

\begin{abstract}
A mobile telephone system is designed to facilitate better communication among 8000 users in the centre of Roma. The network performance prediction tool was used to determine the best location for deployment of the base station. It was based on some parameters or predictions which were obtained by calculating needed data to construct the base station.

Theoretically call planning, cell splitting, frequency re-use, offered traffic etc. techniques are used to obtain a good coverage for a certain city. In order to find the best cell cluster, many calculations were also implemented.

The objective achieved was designing a network system in city centre of Roma. The 7 cell cluster and 12 cell cluster was selected for its overall efficiency. In addition to this, co-channel interference, best server, maximum received power etc. were examined for deployment of the base station with help of Winprop.
\end{abstract}

Key Words:Mobile telephone system, Cell cluster, Frequency re-use, Network performance, Power, Winprop.

\section{INTRODUCTION}

Mobile phone infrastructure is necessary for working of mobile phones in a particular area. The infrastructure involves BS (base station), and MSC (mobile switching centre), BTS (base transceiver station). The universal phone framework (regardless of the fact that it some time or another gets multi gigabit end to-end filament) can at present not fulfil a developing aggregation of clients: individuals on the go [1].

Subsequently, there is a huge measure of investment in remote telephony. In these areas we will concentrate on this subject in some part [2]. Wireless phones come in two fundamental assortments: cordless telephones and cell phones. Cordless telephones are apparatuses comprising of a base station and a handset sold as a set for utilization inside the home. The aforementioned are never utilized for systems administration, so we won't inspect them further.

In this modern world, wireless communication system plays a vital role and it used to overcome the amount of user's capacity in a coverage area. With the deployment of $3 \mathrm{G}$ cellular Technologies since 2000 and more recently High Speed Packet Access (HSPA), there has been a dramatic growth in both the number of subscribers and the volume of data traffic transported by these sophisticated wireless systems.

In a mobile communication system, areas are allocated dedicated radio frequencies. In order to ensure that those channels are not effected by transmissions from other users operating at the same frequency, sufficient separation between the transmitters must be allowed for when allocating the frequencies. In a cellular system, frequency re-use is achieved by assigning a subset of the total number of channels available to each base station, and controlling the power output of the transmitters. In this way, cellular networks capacity increases. Adjacent cells are not allowed to operate at the same frequency since this causes interference between the cells $[3,4,5]$.
COST 231 Walfisch-Ikegami Model, considers the building in the vertical plane between the transmitter and the receiver. Street widths, buildings heights as well as transmitter and receiver heights are considered. The accuracy of this empirical model is quite high because in urban environments the propagation in the vertical plane and over the rooftops (multiple diffractions) is dominating when the transmitters are especially mounted above roof top levels. If the wave guiding effects due to multiple reflections in streets are dominating, the accuracy of the COST WalfischIkegami model is limited - because it is focused on the multiple diffractions in the vertical plane $[6,7]$.

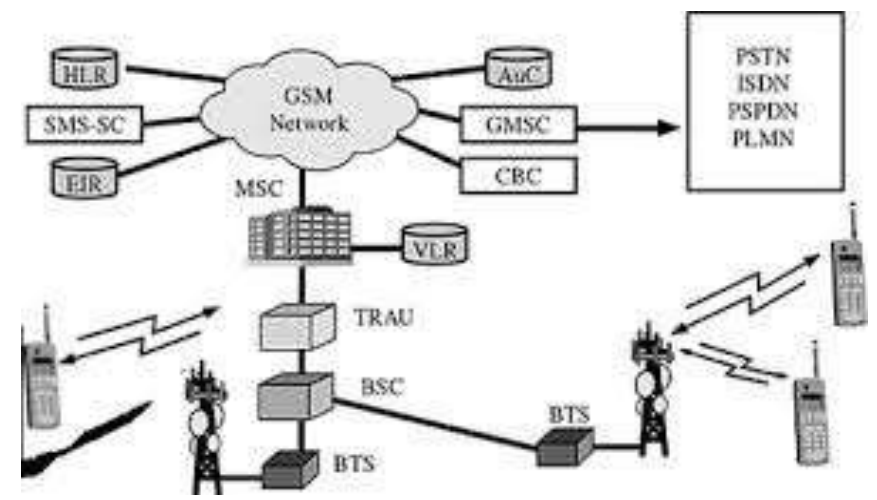

Fig 1:GSM Architecture [8]

A GSM network Basic GSM network diagram is given in figure 1 .

\section{METHOD AND CALCULATION}

Coverage area estimation

Using the probability density function of the received power under long-term fading conditions, the outage probability given by

$$
P_{\text {out }}(R)=0.5 * \frac{\operatorname{erfc}(\ln (\boldsymbol{m}))}{\sigma * \sqrt{2}}
$$


where $\sigma$ is standard deviation of signal fading which is given as $8 \mathrm{~dB}$

In order to convert $\sigma$

$$
\begin{gathered}
\boldsymbol{\sigma}=\left(\frac{\mathbf{1}}{\mathbf{1 0}}\right) * \ln (\mathbf{1 0}) * \boldsymbol{\sigma d} \boldsymbol{B} \\
\sigma=\left(\frac{1}{10}\right) * 2.30 * 8=1.84
\end{gathered}
$$

Substitute standard deviation and outage probability value in outage probability equation.

Given the outage probability of no more than $3 \%$

$$
\begin{gathered}
\boldsymbol{P}_{\text {out }}(\boldsymbol{R})=\mathbf{0 . 5} * \boldsymbol{\operatorname { e r f c }}(\ln (\boldsymbol{m})) /(\boldsymbol{\sigma} * \sqrt{\mathbf{2}}) \\
0.03=0.5 * \operatorname{erfc}(\ln (\mathrm{m})) /(1.84 * \sqrt{2}) \\
\operatorname{erfcinv}(0.06)=\ln (\mathrm{m}) / 2.6
\end{gathered}
$$

Using matlab with help of given code, erfcinv is calculated

$$
\begin{gathered}
\operatorname{erfcinv}(0.06)=1.3299 \\
\ln (m)=1.3299 * 2.60=3.464 \\
m=e^{3.464}=31.95
\end{gathered}
$$

The margin, $M(\mathrm{~dB})$ is given by

$$
M=10 *\left[\log _{10} P_{0}(R)-\log _{10} P_{t h}\right]
$$

$$
\text { (dB) }
$$

Redefining the fading margin in terms of a scaling factor, $m$

$$
\begin{gathered}
M=10 * \log _{10} \frac{P_{0}(R)}{P_{t h}}=10 * \log _{10} \mathrm{~m} \\
M=10 * \log _{10} \mathrm{~m}=10 * \log _{10} 31.95=15.04 \mathrm{~dB} \\
\text { Threshold power is calculated by } \\
\boldsymbol{P}_{\text {th }}=\boldsymbol{P}_{\text {noise }}+\text { Margin } \\
P_{\text {th }}=-105+15.04=-89.96 \mathrm{~dB}
\end{gathered}
$$

\subsection{Calculation for 7 Cell Cluster}

- If a 7 cell cluster is used,

\section{Given that}

- 8000 users

- 500 channels

7 cell cluster has $\mathbf{5 0 0 / 7}=\mathbf{7 1}$ channels

Offered traffic, $\mathbf{A}=\mathbf{6 0 . 0 8} \mathbf{~ E r l / c e l l ~ ( f r o m ~ t a b l e ) ~ w a s ~ f o u n d . ~}$

Carrier traffic,

$$
\boldsymbol{A}_{c}=A\left[1-P_{\text {out }}(R)\right]
$$

$$
A_{c}=60.08 *(1-2 \%)=58.87 \mathrm{erl} / \mathrm{cell}
$$

For 7 cell cluster, total carrier traffic,

$$
A_{t c}=A_{c} * 7
$$

$$
A_{t c}=58.87 * 7=412.09 \text { erlang }
$$

Assuming average telephone use is $5 \mathrm{mins} /$ hours/users

Traffic intensity $A_{I}=\frac{\text { calls }}{\text { hour }} x$ call duration

$$
A_{I}=5 x \frac{1}{60}=0.0 .83333 \text { erl per users }
$$

Total traffic intensity, $A_{T I}=8000 * 0.083333$ $=666.66 \mathrm{erl}$ for 8000 users

Total number of cluster $=\frac{\text { Total traffic intensity }}{\text { total carrier traffic }}$

$$
\begin{aligned}
& \text { Total number of cluster }=\frac{664}{412.09} \\
& \quad=1.61 \text { cluster per square kilometre }
\end{aligned}
$$

Surface area of hexagon $=$ Area of cell $\mathrm{A}=\frac{3 \sqrt{3}}{2} R^{2}$

$$
\begin{gathered}
\frac{666.67 \frac{\mathrm{erl}}{\mathrm{km}}}{58.8 \frac{\mathrm{erl}}{\mathrm{cell}}}=11.34 \mathrm{cell} / \mathrm{km}^{2} \\
11.33 \mathrm{cell}=\mathrm{km}^{2} \\
\mathrm{~A}=\frac{3 \sqrt{3}}{2} R^{2}=\frac{1}{11.33} \gg \gg R=0.184 \mathrm{~km}
\end{gathered}
$$

Signal to CCI ratio is given by

$$
\frac{S}{I}=\frac{1}{N_{I}}\left(\frac{D}{R}\right)^{v}=\frac{1}{N_{I}}\left(3 N_{c}\right)^{v / 2}
$$

In order to calculate the distance

$$
\begin{gathered}
\frac{1}{6}\left(\frac{D}{R}\right)^{v}=\frac{1}{6}\left(3 N_{c}\right)^{v / 2} \\
\frac{1}{6} \frac{D}{0.184}=\frac{1}{6}(3 * 7)^{1 / 2} \\
D=0.84 \mathrm{~km}
\end{gathered}
$$

2.1.1 Efficiency for 7 cell cluster:

Trunking efficiency $=$ carrier traffic/channels

$$
\begin{aligned}
\text { Trunking efficiency } & =58.87 / 71=82.9 \% \\
\text { Signal to CCIratio } & =\frac{\boldsymbol{S}}{\boldsymbol{I}}=\frac{\mathbf{1}}{\boldsymbol{N}_{\boldsymbol{I}}}\left(\frac{\boldsymbol{D}}{\boldsymbol{R}}\right)^{v}
\end{aligned}
$$

Assuming loss component $v=4$

Converting $S / I$ to $(S / I) d B$

$$
\frac{S}{I}=\frac{1}{6}\left(\frac{0.84}{0.184}\right)^{4}=72.39
$$

$$
(S / I)_{d B}=10 \log \left(\frac{S}{I}\right)=10 \log (72.39)=18.59 \mathrm{~dB}
$$

Signal to noise ratio and signal to CCI are equal because of having negligible noise power at the receiver.

As $P_{\text {noise }}=-105 \mathrm{dBm}$ is given,

If we convert the noise power to $\mathrm{W}$, it will be $3.162 \times 10^{-14}$

$$
\text { Received power }=\frac{S}{N} * P_{\text {noise }}
$$

$$
\begin{gathered}
\text { Received power }=73.46 * 3.162 \times 10^{-14} \\
=2.322 \times 10^{-14} \mathrm{~W} \\
=-86.3 \mathrm{dBm}
\end{gathered}
$$

For 8000 users, 


\subsection{Calculation for 12 Cell Cluster}

- If a 12 cell cluster is used

All calculations will be repeated for 12 cell cluster as it was done for 7 cell cluster above.

\section{2 cell cluster has $\mathbf{5 0 0 / 1 2}=\mathbf{4 1 . 6 6}$ channels}

Offered traffic, $\mathbf{A}=\mathbf{3 1 . 9 1 6} \mathbf{E r l} /$ cell (from table) was found.

Carrier traffic, $A_{c}=A\left[1-P_{\text {out }}(R)\right]$

$$
A_{c}=31.916 *(1-2 \%)=31.27 \mathrm{erl} / \mathrm{cell}
$$

For 12 cell cluster, total carrier traffic, $A_{t c}=A_{c} * 12$

$$
A_{t c}=31.916 * 12=375.33 \text { erlang }
$$

Assuming average telephone use is 5 mins/hours/users

Traffic intensity $A_{I}=\frac{\text { calls }}{\text { hour }} x$ call duration

$$
A_{I}=5 x \frac{1}{60}=0.0 .83333 \mathrm{erl} \text { per users }
$$

For 8000 users,

Total traffic intensity, $A_{T I}=8000 * 0.083333$

$$
=666.66 \mathrm{erl} \text { for } 8000 \text { users }
$$

Total number of cluster $=\frac{\text { Total traffic intensity }}{\text { total carrier traffic }}$

Total number of cluster $=\frac{666.66}{375.33}=1.77$ cluster perkm ${ }^{2}$

Surface area of hexagon $=$ Area of cell $\mathrm{A}=\frac{3 \sqrt{3}}{2} R^{2}$

$$
\begin{gathered}
\frac{666.67 \frac{\mathrm{erl}}{\mathrm{km}^{2}}}{31.27 \frac{\mathrm{erl}}{\mathrm{cell}}}=21.32 \mathrm{cell} / \mathrm{km}^{2} \\
21.32 \mathrm{cell}=\mathrm{km}^{2} \\
\mathrm{~A}=\frac{3 \sqrt{3}}{2} R^{2}=\frac{1}{21.32} \gg \gg R=0.134 \mathrm{~km}
\end{gathered}
$$

Signal to CCI ratio is given by

$$
\frac{S}{I}=\frac{1}{N_{I}}\left(\frac{D}{R}\right)^{v}=\frac{1}{N_{I}}\left(3 N_{c}\right)^{v / 2}
$$

In order to calculate the distance

$$
\begin{gathered}
\frac{1}{6}\left(\frac{D}{R}\right)^{v}=\frac{1}{6}\left(3 N_{c}\right)^{v / 2} \\
\frac{1}{6} \frac{D}{0.134}=\frac{1}{6}(3 * 7)^{1 / 2} \\
D=0.804 \mathrm{~km}
\end{gathered}
$$

\subsubsection{Efficiency for 12 cell cluster:}

Trunking efficiency $=$ carrier traffic $/$ channels Trunking efficiency $=31.916 / 41.66=76 \%$

$$
\text { Signal to CCIratio }=\frac{S}{I}=\frac{1}{N_{I}}\left(\frac{D}{R}\right)^{v}
$$

Assuming loss component $v=4$

$$
\frac{S}{I}=\frac{1}{6}\left(\frac{0.804}{0.134}\right)^{4}=216
$$

Converting $S / I$ to $(S / I) d B$,

$$
(S / I)_{d B}=10 \log \left(\frac{S}{I}\right)=10 \log (216)=23.34 d B
$$

Signal to noise ratio and signal to CCI are equal because of having negligible noise power at the receiver.

$$
\frac{S}{N}=216 \mathrm{~W}
$$

As $P_{\text {noise }}=-105 \mathrm{dBm}$ is given,

Converting it to $\mathrm{W}$, it will be $3.162 \times 10^{-14} \mathrm{~W}$

$$
\text { Received power }=\frac{S}{N} * P_{\text {noise }}
$$

Received power $=216 * 3.162 \times 10^{-14}=6.83 \times 10^{-12} \mathrm{~W}$

$$
=-81.3 \mathrm{dBm}
$$

Threshold power is calculated by

$$
\begin{gathered}
P_{t h}=P_{\text {noise }}+\text { Margin } \\
P_{t h}=-105+15.04=-89.96 \mathrm{~dB}
\end{gathered}
$$

As it is seen from the efficiency both 7 cell cluster and 12 cell cluster for 8000 users in centre of Roma, 7 cell cluster is more efficient than 12 cell cluster.

\subsection{Power}

The COST 231 Walfisch-Ikegami model was used to calculate both power loss and transmitter power by using matlab code in Roma. The formula of this model is dependent on the frequency, the height of transmitter and receiver, distance between transmitter and receiver, etc. The figure 1 was obtained

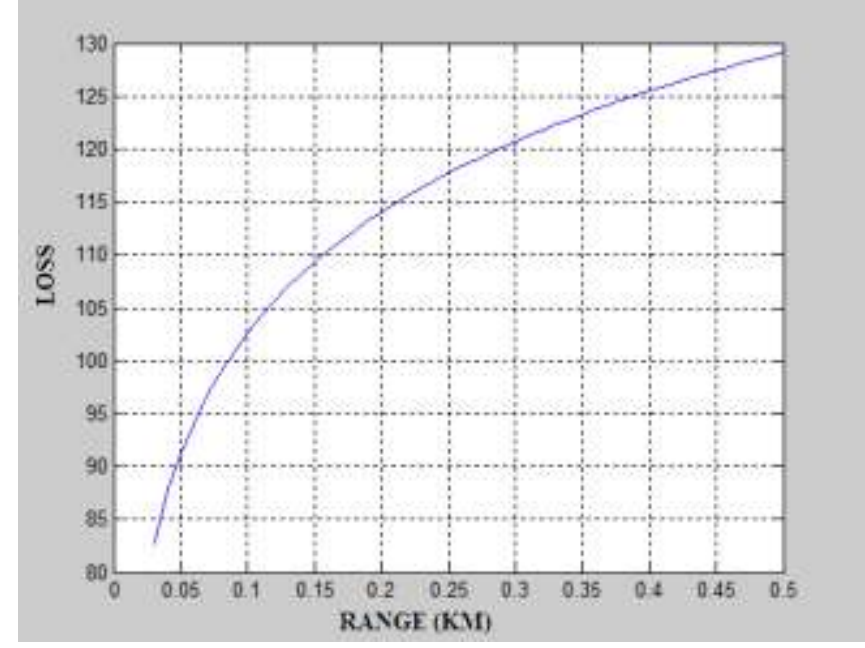

Fig 2: Power Loss using COST 231 Walfisch-Ikegami Model

The radius of $0.184 \mathrm{~km}$ was found from calculation above; according to this radius, path loss $(113 \mathrm{~dB})$ was obtained from the figure 2 .

The constant values:

- Frequency: $1800 \mathrm{MHz}$

- Height of the transmitter: $25 \mathrm{~m}$

- Height of the receiver: $1.5 \mathrm{~m}$

Approximation values:

- Building heights $28 \mathrm{~m}$

- Widths of streets $17 \mathrm{~m}$

- Building separation: $28 \mathrm{~m}$

Transmitted power is calculated using below equation with help of COST 231 Walfisch-Ikegami Model. 


$$
P_{\text {trasnmitted }}=P_{\text {threshold }}+L_{\text {pro }}+M
$$

$P_{T}=-89.95+113.5+15=38.54 \mathrm{dBm}=7100 \mathrm{~mW}$

In this section, all used formulas were taken from the following sources $[9,10]$.

\section{WINPROP RESULTS}

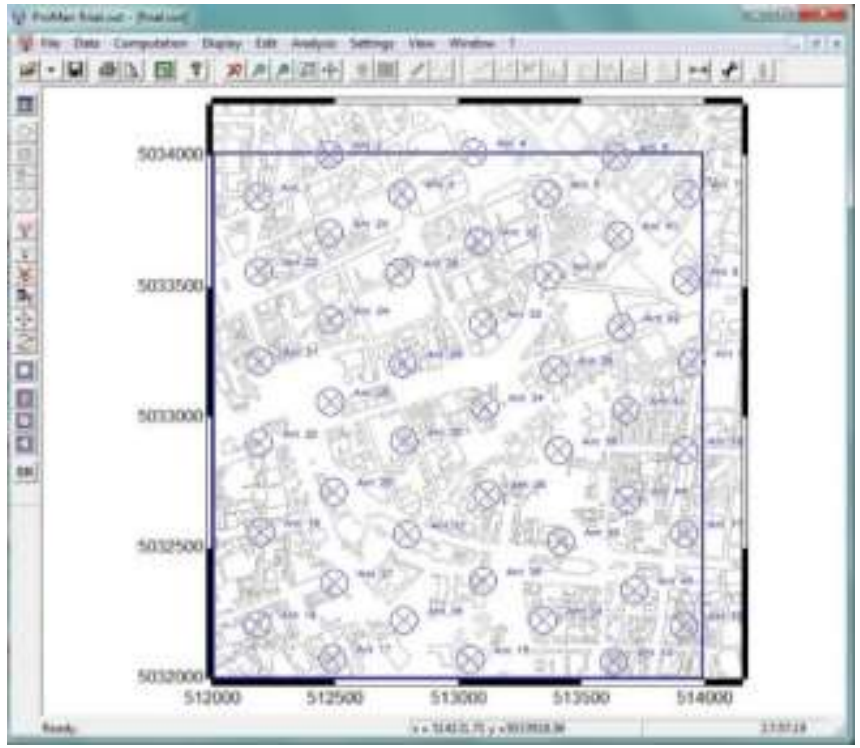

Fig 3: The city of Roma with trasnmitters ( 2 by 2 area)

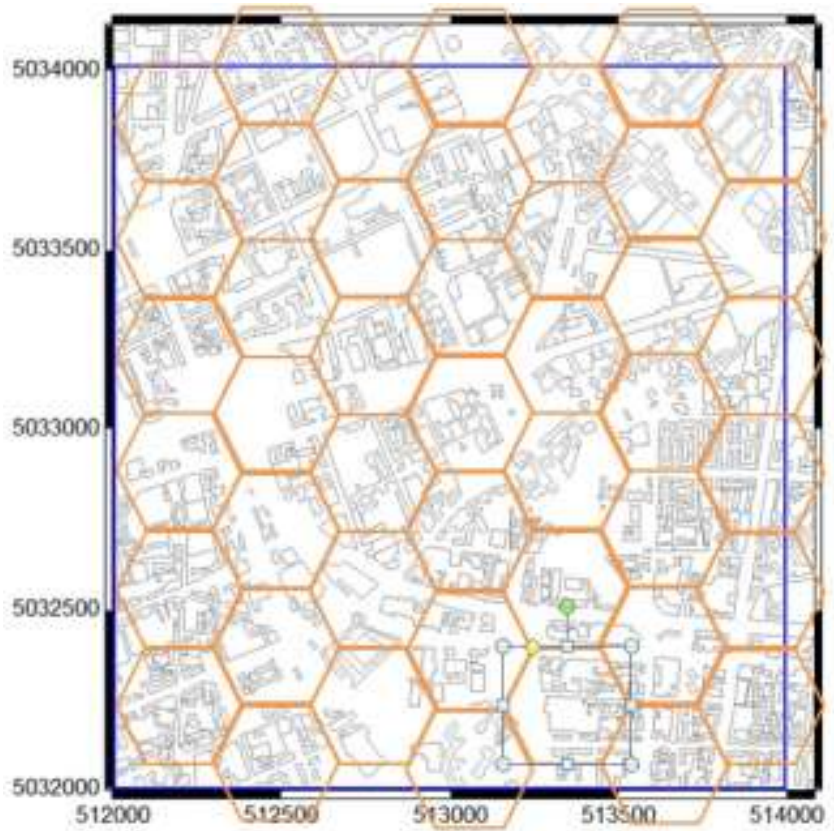

Fig 4 (a): Computational area by dividing into cells and interference cells are shown

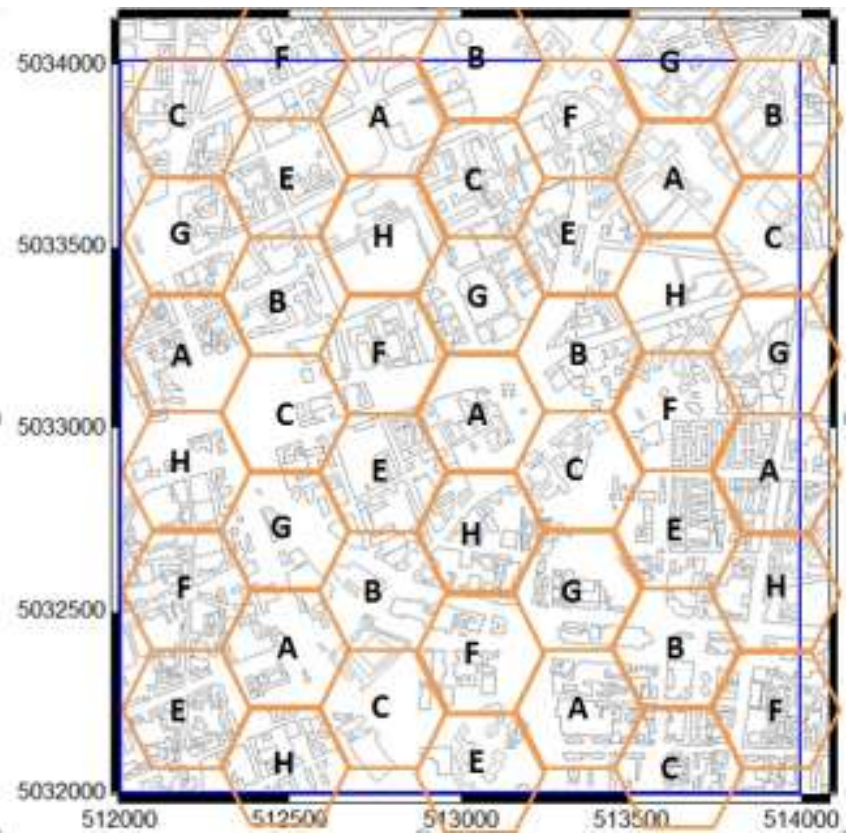

Fig 4 (b): Computational area by dividing into cells and interference cells are shown

As it is found that 11.32 cells per square kilometre gives a total of approximately 45 cells in the 2 by 2 area. Therefore, 45 antennas were used to get better signal according to above calculations. Also, this 2 by 2 computational are divided into these much cells and these antennas were placed in accordance with above map. As it is seen from the figure 4, interference cells which were defined indicated with letters. The cells with same letter were used same channel (carrier).

Table 1: Channels with antennas

\begin{tabular}{|c|c|c|c|c|c|c|}
\hline Uَّ & نِّ & 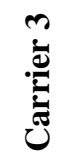 & Uై & 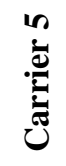 & שֶّ & שَّ. \\
\hline $\mathbf{A}$ & B & C & H & $\mathbf{E}$ & $\mathbf{F}$ & $\mathbf{G}$ \\
\hline Ant & Ant & Ant & Ant & Ant & Ant & Ant \\
\hline 3 & 4 & 1 & 11 & 15 & 2 & 6 \\
\hline Ant & Ant & Ant & Ant & Ant & Ant & Ant \\
\hline 10 & 7 & 8 & 17 & 18 & 5 & 9 \\
\hline Ant & Ant & Ant & Ant & Ant & Ant & Ant \\
\hline 14 & 24 & 13 & 20 & 23 & 12 & 22 \\
\hline Ant & Ant & Ant & Ant & Ant & Ant & Ant \\
\hline 21 & 31 & 16 & 28 & 30 & 19 & 26 \\
\hline Ant & Ant & Ant & Ant & Ant & Ant & Ant \\
\hline 27 & 38 & 25 & 35 & 37 & 29 & 33 \\
\hline Ant & Ant & Ant & Ant & Ant & Ant & Ant \\
\hline 34 & 45 & 32 & 42 & 44 & 36 & 40 \\
\hline $\begin{array}{c}\text { Ant } \\
41\end{array}$ & & $\begin{array}{c}\text { Ant } \\
39\end{array}$ & & & $\begin{array}{c}\text { Ant } \\
43\end{array}$ & \\
\hline
\end{tabular}




\subsection{Co-channel Interference}

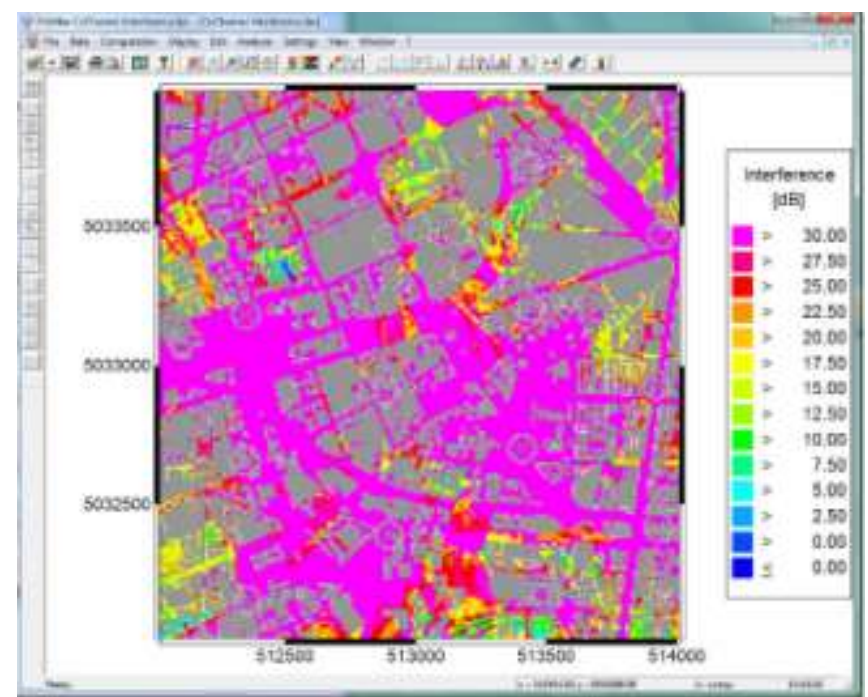

Fig 5: Co-channel Interference

As it is seen from the figure 5, the area around the transmitter was covered with a good signal. Most of the area was covered with the $\mathrm{S} / \mathrm{I}$ of more than $30 \mathrm{~dB}$. In the some places there is a co-channel interference which is very low. In order to get better signal, less cell size were used. At the same time, avoiding the problem of indoor coverage, the antennas were placed on the top of the building at 4 meter above.

\subsection{Best Server}

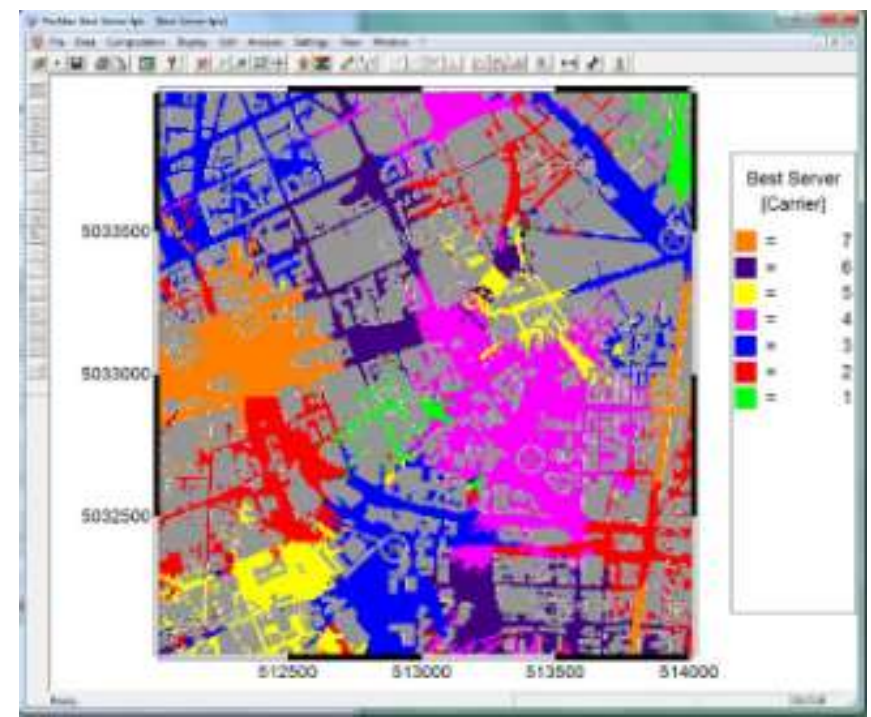

Fig 6: Best Server

As it is seen from the figure, 7 different channels were used to prevent the interference. Each colour shows the antenna signal. The signal power is normally strong around the transmitter. It is getting weaker away from the antenna. Some antennas were covered more area than the others because different obstacles effected the antennas. The radius of the hexagon is $0.184 \mathrm{~km}$. therefore the frequency reuse distance was found more than $0.890 \mathrm{~km}$.

\subsection{Maximum Power}

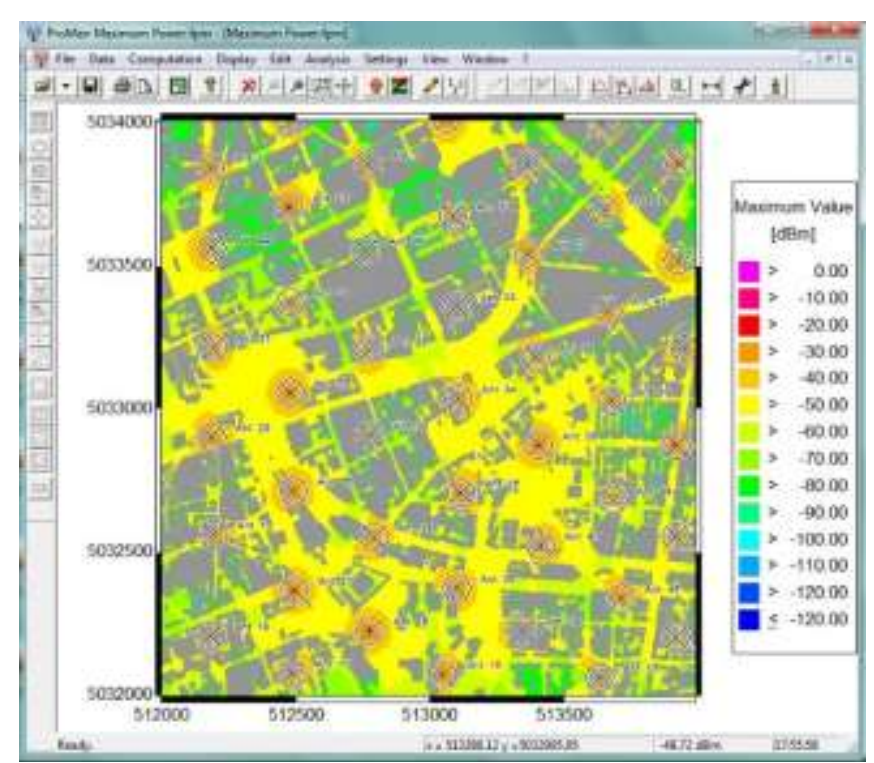

Fig 7: Maximum Power

The maximum power map shows the user can get the signal from the station until $-90 \mathrm{dBm}$. As the maximum power reaches the threshold power which is $-88.5 \mathrm{dBm}$, power is good enough to communicate. As it is seen in the figure, the power is less in some areas than threshold power because of some obstacles or interference of the other base station.

\subsection{Cell Area}

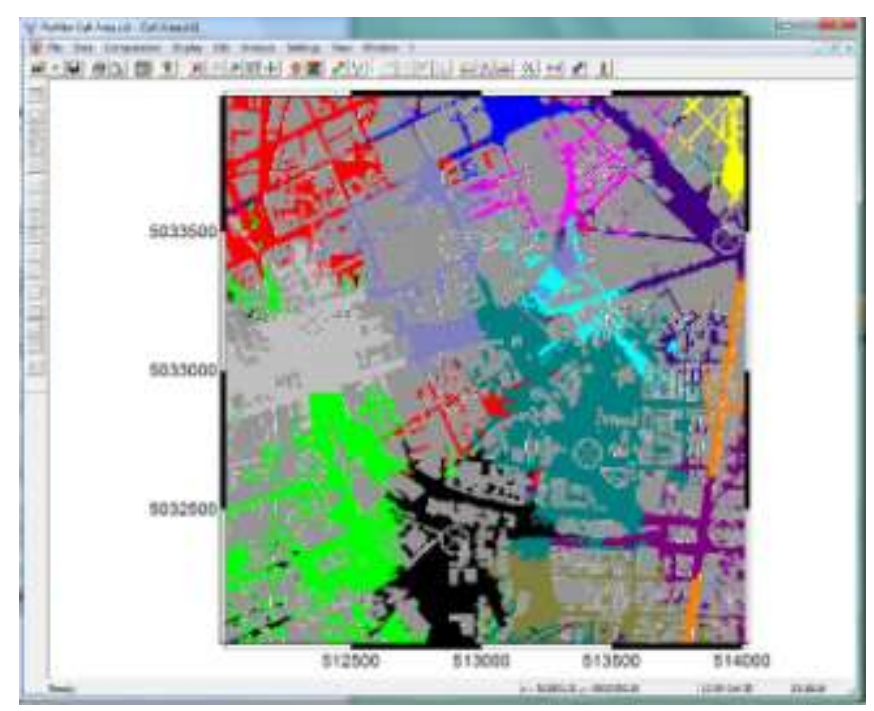

Fig 8: Cell area

Cell area illustrates distance covered by a base station signals for a certain area. The signal is transmitted to a particular area by base station, if the user gets the signal from both stations it is handover process which occur because different channel were used to prevent the interference. In some area, the signal power is less because there are some areas covered by some obstacles like underground. 


\subsection{Number of Received Channels}

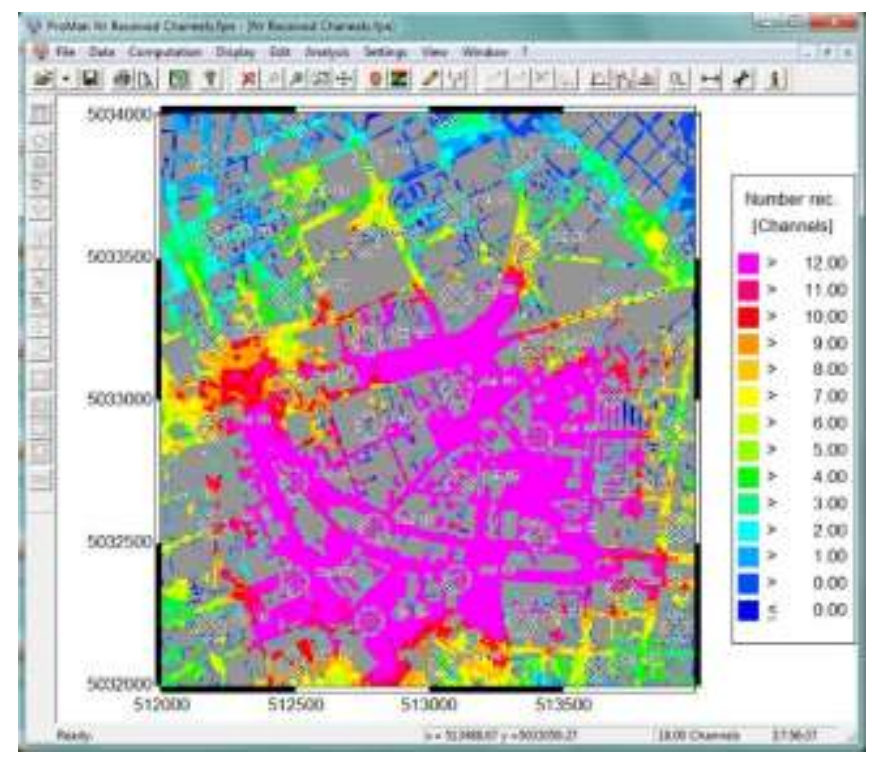

Fig 9: Number Received of Channel

Number of received channels is seen in figure 9. Ideally, each pixel (mobile station) would be covered by 1 base station only.

\section{DISCUSSION}

Torre Europarco is the tallest building at the centre of Rome, and it is feasible for the installation of mobile base station. Cell frameworks are considerably utilized today and cell engineering ought to offer exceptionally productive utilization of the organized recurrence range. With billions of versatile telephones in utilization around the globe today, it is vital to re-utilize the obtainable frequencies numerous times over without shared obstruction of one wireless to another. It is this idea of recurrence re-utilize that is at the exact heart of cell innovation. However the base innovation would have done well to back it is not straightforward, and it needed a huge speculation to carry the first cell systems on line [11].

\section{Base Station (BS)}

Base station consists of GSM antennas and these antennas are interrelated with each other by means of wireless or wired communication. In Rome, it is necessary to provide a base station which can handle the customers in a specific area of Rome. Mobile phones connect with the base station by means of cells. The area of coverage of each cell depends upon its deployment method. The efficiency of Base Station can be improved, if we keep the size of cells small, and install massive antennas. In this scenario, macro cells will be used. It is necessary for macro cells to be installed on height. It covers the area of approx. 30kilometers. The frequency commonly used in Rome is $900 \mathrm{MHz}$ or $1800 \mathrm{MHz}$ frequency bands. The transmission power will be 2 watts [12].

\section{Cell clusters}

The group of cells is called cluster. The phenomenon of frequency re-use for increasing the number of users within a cluster. In the base station of Rome, frequencies utilize in one cell cluster may also be used in another cell cluster.

\section{Cell size}

Macro cells are used in this cellular design to increase the coverage area of BS. In spite of the fact that the amount of cells in a cluster in a cellular framework can assist legislate the amount of clients that could be suited, by making all the cells more diminutive it is conceivable to build the on the whole limit of the cellular framework. However a more excellent number of transmitter beneficiary or base stations are needed if cells are made more modest and increase the operating cost. Likewise in ranges where there are more clients, minor level control base stations are established.

\section{Frequency re-use}

This method is used in this cellular system, to increases the number of users in an area. The system that is utilized is to empower the frequencies to be re-used. Any radio transmitter will just have a certain scope area. The same is likewise correct in the reverse direction for the receiver, where it can just receive motions over a given extend. This method can be used in base station of Rome to increase the number of users in an area.

\section{Co-channel Interference}

In a GSM system, the amount of frequencies accessible to the admin is constrained. Therefore, the frequencies must be reused over the system area. Co-channel interference may occur in the base station of Rome. To reduce the co-channel interference, it is necessary to maintain co-channel cells at some distance with each other. This base station uses directional antennas, which helps to reduce co-channel interference.

\section{Cell Splitting}

Cell splitting is the process of dividing the radio coverage of a cell site in a wireless telephone system into two or more new cell sites. It will increase the capacity of users in the centre of Rome.

\section{Fading and Fading margin}

In wireless correspondences, fading is difference of the constriction that encounter via bearer regulated telecommunication motion over the medium of spread. Fade Margin is an expression for what amount of margin -in $\mathrm{dB}$ there is between the received indicator strength level and the receiver affectability of the radio.

\section{Estimation of traffic}

It covers the area of 30kilometers and range can be increased by using more base stations. It covers approximately 30-40 thousands users at a time and it can be increased by increasing the no of cells.

\section{Weakness/Strength}


This GSM network is more stable and robust because of use of quality equipment. It has the ability to use repeaters. On the top of the building and because of centre of Rome, the chance of interference from different appliances becomes increase.

No of Cells

No of cells are important in controlling the traffic from the base station. The no of cells should be 7 because; it helps in frequency re-use scenario.

\section{CONCLUSION}

The design project was performed in order to design a mobile telephone system in the centre of Roma. It was done by using 7 cell cluster and 12 cell cluster. 7 cell clusters gave better result for deployment of base stations. Assuming telephone use is 5 minutes per hour per user. At peak time there are 8000 users of the network in each square kilometre of the city. It is allocated 500 channels for the network and calls must not be blocked due to unavailable bandwidth for no more than $2 \%$. The area which is quite small is 4 square kilometres but 32000 users will communicate. The frequency reuse helped us to overcome the bandwidth limitation in this design. Although some areas have low signal strength, in a nutshell the system is working properly.

\section{REFERENCES}

[1]. 'Global System for Mobile Communication' http://www.tutorialspoint.com/gsm/gsm_architecture.htm, accessed 02/03/2014

[2].Hassoy et al. Adolescents' risk perceptions on mobile phones and their base stations, their trust to authorities and incivility in using mobile phones: a cross-sectional survey on 2240 high school students in Izmir, Turkey. Environmental Health 2013.

[3].Wang C. 'Performance Analysis of Cellular Mobile Communication Systems for Data Transmission'. IEEE Transactions on Vehicular Technology, Vol. 44, No.1, 1995

[4].Lee W.C.Y. Mobile Cellular Telecommunications Analog and Digital Systems. 2nd Edition, McGraw-Hill, Inc Chapter 16

[5].RajkumarPeriannan\&Fadi Joseph Fahham. Performance Issues of Cellular Networks. http://www.doc.ic.ac.uk/ nd/surprise_96/journal/vol4/fjf/rep ort.html, accessed 25/05/2014

[6].DongsooHar, Alix M. Watson, and Anthony G. Chadney. Comment on Diffraction Loss of Rooftop-to-Street in COST 231-Walfisch-Ikegami Model IEEE Transactions On Vehicular Technology, Vol. 48, No. 5, 1999

[7].http://www.awecommunications.com/Propagation/Urban/ COST/accessed 25/05/2014

[8]. 'GSM-Architecturetutorials'

http://www.tutorialspoint.com/gsm/gsm_architecture.htm, accessed 19/03/2014.

[9]. Gordon L. Stüber. Principles of Mobile Communication. Third Edition Springer, 2011.

[10]. Bernard H. Walke. Mobile Radio Networks. 2nd Edition. John Wiley\& Sons, 2002.

[11].Jalil, R., Ergen, M. 'Method and Apparatus to Estimate Relative Base Station and Subcriber Terminal Locations and
Using It to Increase Frequency Reuse'. United States Patent Application 20130016660, 2013

[12].Kuehn, S., Kelsh, M. A., Kuster, N., Sheppard, A. R., and Shum, M. 'Analysis of mobile phone design features affecting radiofrequency power absorbed in a human head phantom'. Bioelectromagnetics, 2013 